\title{
Citologia do lavado broncoalveolar de eqüinos da Polícia Militar do Distrito Federal
}

Nathalia dos Santos COSTA ${ }^{1}$ Delphim da Graça MACORIS $^{1}$

\section{Correspondência para:}

Nathalia dos Santos Costa

SHIN QI 06 Cojunto 03 Casa 19

Lago Norte 71520-030 Brasília-DF

Recebido para publicação: 21/10/2005 Aprovado para publicação: 07/02/2007

\author{
1 - Faculdade de Ciências Agrárias e Veterinárias, Universidade Estadual \\ Paulista, Jaboticabal, SP
}

\section{Resumo}

O objetivo deste trabalho foi avaliar os tipos celulares das vias aéreas de eqüinos da Polícia Militar do Distrito Federal. Foram utilizados 24 eqüinos, distribuídos em 2 grupos de 12: grupo I - animais em ronda e grupo II - animais afastados da escala. Ao exame físico e hematológico, os resultados foram compatíveis com a ausência de afecções clínicas. Na lavagem broncoalveolar (LBA), foram infundidos $240 \mathrm{~mL}$ de solução salina. Nos LBAs, o grupo I registrou

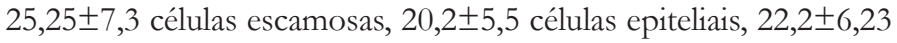
macrófagos e 2,02 $\pm 5,77$ eritrócitos. Nos LBAs do grupo II,

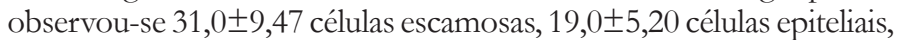

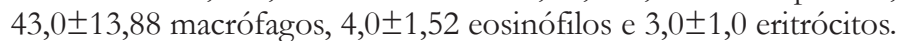
$\mathrm{Na}$ verificação de complicações pós-experimento, não foram registradas seqüelas advindas da técnica de colheita.
Palavras-Chave: Broncoalveolar. Citologia. Eqüino. Lavado.

\section{Introdução}

Os estudos das secreções do trato respiratório, em diferentes segmentos anatômicos, vêm constituindo recurso semiológico importante, mediante a observação dos sinais aparentes, como complemento do diagnóstico das afecções respiratórias, capazes de ensejar resultados objetivos, confiáveis e definidores das etiologias e prognósticos referentes às doenças ${ }^{1,2,3}$.

As secreções do trato respiratório podem ser colhidas em diferentes níveis das vias aéreas e mediante vários métodos. $\mathrm{O}$ lavado broncoalveolar (LBA) realizado em eqüinos, segundo $\mathrm{Ames}^{4}$, contribui na precisão do diagnóstico. Essa técnica proporciona acesso seguro e não invasivo às vias aéreas distais, mediante instilação de líquido e subseqüente aspiração do conteúdo fluido e dos tipos celulares presentes no lavado $^{3,5}$.

O LBA permite ao clínico diagnosticar doenças das vias aéreas inferiores em um estágio inicial quando ainda não há sinais suficientes como tosse ou exsudato traqueal. O LBA, após citocentrifugação e exame microscópico revela, principalmente, neutrofilia, eosinofilia e aumento no número de mastócitos, o que o torna um importante instrumento não apenas no diagnóstico de doenças das vias aéreas inferiores, como também na conduta da terapia ${ }^{6}$.

Em relação à taxa de recuperação ou à porcentagem do fluido instilado que é recuperada no lavado broncoalveolar, esta depende do número de alíquotas instiladas, do volume total infundido, e da integridade do parênquima pulmonar. Várias alíquotas de fluido instilado podem aumentar a taxa de recuperação deste. Muitos autores têm relatado um declínio na taxa de recuperação do fluido instilado em eqüinos com obstrução recorrente das vias aéreas (ORVA) quando comparada com a taxa de recuperação em eqüinos normais ${ }^{4}$. $\mathrm{O}$ mecanismo sugerido para explicar o decréscimo da taxa de recuperação é que a 
ORVA induz ao estreitamento das vias aéreas, obstando a aspiração do fluido instilado ${ }^{7}$.

A presença de uma camada de espuma sobre o líquido recuperado indica que o surfactante está presente e, além disso, que o lavado alcançou o território alveolar. A aparência amarelo-opaca com tonalidade vermelho-alaranjada pode indicar prévia hemorragia e inflamação. Características físico-químicas do lavado recuperado como $\mathrm{pH}$, seu conteúdo de eletrólitos e sua temperatura, podem afetar a quantidade de células presentes ${ }^{4}$.

No LBA, as células predominantes são macrófagos alveolares e células epiteliais. Variações estão relacionadas às técnicas de colheita, tempo de recuperação do lavado e interpretação. Os tipos celulares encontrados guardam estreita relação com a natureza do processo patológico, como segue: (I) aumento de neutrófilos está associado à inflamação (doença respiratória crônica, pneumonia, pleuropneumonia); (II) quantidade significativa de hemossiderófagos associa-se à hemorragia pulmonar induzida por exercício; (III) presença marcante de eosinófilos relaciona-se à doença alérgica; (IV) predomínio de células epiteliais compatibilliza-se com eqüinos normais; e (V) aumento de neutrófilos, linfócitos, macrófagos e monócitos ocorre em cavalos com doença respiratória crônica ${ }^{8}$.

Em estudo referente às partículas em suspensão no ambiente das cocheiras, foram identificadas mais de 50 espécies de fungos, leveduras, grande número de ácaros na forragem, endotoxinas e componentes inorgânicos ${ }^{9}$.

A atmosfera das instalações dos animais consiste de uma mescla variável de agentes, muitos dos quais podem induzir ou exacerbar inflamações pulmonares. A importância concernente de cada um desses agentes na etiologia dos distúrbios das vias aéreas é desconhecida, sendo provável que a patogenicidade de alguns agentes, por exemplo, dos fungos, seja potencializada pela presença de outros tais como, endotoxinas bacterianas ${ }^{10}$.

Um problema potencial com o LBA é que, como o material é colhido de apenas uma área pulmonar, os resultados podem não ser representativos do restante do órgão, especialmente, quando se trata de lesões localizadas em outras partes do pulmão .

Apesar de o LBA ser considerado técnica não invasiva; ela pode causar seqüela mínima no parênquima pulmonar, como influxo de neutrófilos. Isso pode decorrer da síntese de fatores quimiotáticos pelos macrófagos alveolares ou da ativação da cadeia do complemento ${ }^{4}$.

Como o LBA é um procedimento seguro, facilmente reprodutível e causa poucas complicações ${ }^{11,12}$ pode ser incluído nos procedimentos da rotina clínica de animais com desordens pulmonares difusas. Além disso, com a introdução da técnica de LBA, a compreensão à cerca das células inflamatórias na fisiopatologia das doenças respiratórias de equiinos tem sido ampliada.

O objetivo da presente pesquisa foi avaliar os constituintes celulares das vias aéreas de eqüinos do $1^{\circ}$ Regimento de Polícia Montada Regimento "Coronel Rabelo" da Polícia Militar do Distrito Federal.

\section{Material e Método}

Os procedimentos foram realizados nas dependências da Seção Veterinária do $1^{\circ}$ Regimento de Polícia Montada, com 24 animais sem raça definida, que apresentavam idade variável de seis a 25 anos.

A alimentação individual diária desses animais era constituída por $4 \mathrm{~kg}$ de ração comercial e $4 \mathrm{~kg}$ de feno, divididos em duas porções, sendo o sal mineral e a água fornecidos à vontade. Os animais foram mantidos em cocheiras de alvenaria, todas medindo $3,5 \mathrm{~m} \times 3,5 \mathrm{~m}$, bem arejadas e com três cochos, estes também de alvenaria, para água, ração e sal mineral. A cama das baias constituiu-se de maravalha de pinus, limpa diariamente.

Todos os animais do $1^{\circ}$ RPMon são tratados com vermífugo comercial (ivermectina) a cada 60 dias e vacinados, anualmente, contra tétano, influenza eqüina e encefalomielite. 
Os 24 eqüinos estudados foram distribuídos em dois grupos de doze animais cada: grupo I - animais em atividade de ronda policial diária, sendo mantidos em repouso na véspera e no dia do experimento e grupo II - animais afastados da escala, por diversos motivos, salvo os que apresentavam problemas respiratórios, que eram mantidos em condições nosocomiais.

Os procedimentos diários de avaliação clínica e colheita das amostras sempre foram iniciados pela reunião dos seis animais, mantidos em um piquete próximo à área de trabalho. Então, procedeu-se à aferição do peso corporal e, a seguir, à contenção no brete.

Em um período de quatro dias, os 24 animais foram submetidos a minucioso exame físico, bem como a uma avaliação do quadro hematológico, antes da realização dos lavados das vias aéreas e respectiva recuperação dos fluidos. Para o lavado broncoalveolar, manejou-se seis animais de cada grupo por dia.

\section{Colheitas}

Em seguida ao exame clínico, foram colhidas amostras de sangue através de venopunção da jugular para realização do hemograma. O sangue foi acondicionado em sistema de tubo (Vacutainer com EDTA $\mathrm{BD})$ a vácuo contendo EDTA.

Para colheita do fluido broncoalveolar, cada animal foi contido com aziar e sedado com xilazina 2\% (Coopazine - Coopers Brasil LTDA), na dose de $0,7 \mathrm{mg} / \mathrm{kg}$. O cateter (cateter LBA - Cook Produtos Veterinários), cujo lúmen foi parcialmente preenchido com $5 \mathrm{~mL}$ de anestésico local (Xylestesin 2\% - Cristália - Produtos Químicos e Farmacêuticos LTDA), foi conectado a uma seringa de $20 \mathrm{~mL}$, contendo solução salina (Solução fisiológica $0,9 \% \mathrm{NaCl}$ - Laboratório Sanobiol LTDA), que foi utilizada apenas para carrear o anestésico. Em seguida, avançou-se o cateter ao longo do meato ventral até que a laringe fosse alcançada. Mantendo-se a cabeça do cavalo estendida, o cateter foi introduzido na inspiração. Quando a carina foi alcançada, instilou-se $20 \mathrm{~mL}$ da solução da seringa com o intuito de carrear o anestésico, a fim de dessensibilizar a região, para prevenir o reflexo da tosse quando da passagem do cateter. A seguir, o manguito foi inflado, para fixar o cateter no brônquio. Foram infundidas e imediatamente aspiradas doze alíquotas de $20 \mathrm{~mL}$, totalizando o volume de $240 \mathrm{~mL}$ de solução salina estéril. Finalizada a colheita, as alíquotas recuperadas foram transferidas para frascos com EDTA. As amostras biológicas foram mantidas sob refrigeração até o momento da entrega no laboratório, sendo processadas no máximo em 5 horas.

Em cumprimento ao protocolo de pesquisa estabelecido, foram realizadas quatro visitas adicionais ao $1^{\circ} \mathrm{RPMon} /$ PMDF, com a freqüência de seis em seis dias a partir da data de cada coleta. Nessas visitas, foram realizados exames clínicos com vistas a verificar a ocorrência, ou não, de complicações nos animais pesquisados.

\section{Análises laboratoriais}

Foram encaminhadas 24 amostras de lavados broncoalveolares. Os lavados, devidamente identificados, foram transferidos para tubos cônicos de $15 \mathrm{~mL}$ e levados à centrífuga por 6 minutos, a $3.500 \mathrm{rpm}$. Os sobrenadantes foram desprezados e os sedimentos foram distendidos em lâminas novas e desengorduradas, sob a forma de esfregaços. Tais preparações, após fixadas, foram coradas com corante panótico (Instant Prov NEWPROV Produtos para laboratório). O material, no laboratório, recebeu classificação de acordo com os achados, que consistiram em: artefatos, leveduras, células, muco e bactérias.

A ocorrência de artefatos (material inorgânico e vegetal), muco e bactérias foi quantificada quanto à intensidade em: (I) raros + (1/campo); (II) poucos $++(2$ e $3 /$ campo); (III) moderados +++ (4 a $6 /$ campo); (IV) grande quantidade $++++(7 \mathrm{a}$ 15/campo); (V) incontáveis (+15/campo). 


\section{Análise estatística}

Os resultados foram submetidos à análise descritiva e de estatística para cálculo da média e do desvio padrão. Os dados referentes aos parâmetros clínicos aferidos, volumes recuperados, hemograma e citologia foram tabelados e submetidos à análise de variância de uma única via para avaliação das diferenças entre os grupos.

\section{Resultados}

A inspeção dos animais não revelou qualquer fator negativo quanto à condição física geral e ao estado nutricional. Nos quesitos comportamento, temperamento e expressão facial houve individualidade nas reações às manobras realizadas, o que é, naturalmente, justificado e esperado para a espécie. Quanto à postura, desenvolvimento muscular (atrofia, hipertrofia), cobertura de pêlos, pele e anexos, não houve registros relevantes. $\mathrm{Na}$ inspeção de corrimentos bucais, nasais, oculares, otológicos, genitais ou anais, não houve nenhum achado significativo nos 24 animais estudados. Os valores aferidos no exame físico dos dois grupos, estão exibidos na tabela1.

$\mathrm{Na}$ lavagem broncoalveolar não se registrou resistência à passagem do cateter em nenhum momento. Foi possível recuperar $55 \pm 9,29 \mathrm{~mL}$ no grupo I e $70 \pm 9,29 \mathrm{~mL}$ no grupo II do volume instilado. O surfactante foi observado, em quantidade variável, em todas as amostras colheitadas. Os volumes infundidos e recuperados estão registrados na tabela 2.

Nenhum dos animais estudados apresentou alterações no hemograma. Os achados referentes aos mielócitos, metamielócitos e basófilos foram zero em ambos os grupos. De forma semelhante, a pesquisa de hematozoário foi negativa em todos os animais, integrantes do grupo I e II. Os valores referentes aos hemogramas estão apresentados na tabela 3.

Os achados laboratoriais dos lavados obtidos foram avaliados quanto à quantidade e morfologia celulares, à contagem diferencial das células, quando existentes, e à apreciação de elementos como bactérias, artefatos e muco, como seguem apresentados nas tabelas 4 e 5 .

\section{Discussão}

Ratificando as descrições de Gonçalves, Kuchembuck e Almeida ${ }^{1}$, Gonçalves $^{2}$ e Fernandes, Mori e Sanches ${ }^{3}$, esse experimento menciona a viabilidade da coleta de secreções do trato respiratório e a

Tabela 1 - Valores médios e respectivos desvios-padrão de variáveis clínicas de eqüinos sadios dos grupos estudados. Brasília, 2004.

\begin{tabular}{lcc}
\hline \hline Variáveis clínicas & Grupo I & Grupo II \\
\hline \hline Freqüência cardíaca $/ \mathrm{min}$ & $39 \pm 7,4 \mathrm{~A}$ & $38 \pm 9,6 \mathrm{~A}$ \\
Freqüência respiratória $/ \mathrm{min}$ & $27 \pm 5,1 \mathrm{~A}$ & $28 \pm 5,1 \mathrm{~A}$ \\
Temperatura corpórea $\left({ }^{\circ} \mathrm{C}\right)$ & $38 \pm 0,6 \mathrm{~A}$ & $38 \pm 0,5 \mathrm{~A}$ \\
Peso corporal $(\mathrm{kg})$ & $438 \pm 54,7 \mathrm{~A}$ & $443 \pm 52,8 \mathrm{~A}$
\end{tabular}

$\overline{\text { Valores obtidos a partir daqueles aferidos antes da execução das colheitas de sangue e de material das vias respiratórias. }}$ Letras maiúsculas iguais significam que não houve diferenças significativas entre os grupos $(P<0,05)$

Tabela 2 - Valores do volume infundido $(\mathrm{mL})$ e valores médios e desvios-padrão do volume recuperado $(\mathrm{mL})$ dos lavados broncoalveolares de eqüinos em ronda (GI) e afastados de atividades (GII). Brasília, 2004

\begin{tabular}{cccc}
\hline \hline Técnica de colheita & Grupo & Volume infundido & Volume recuperado \\
\hline \hline LBA & GI & 240 & $55 \pm 9,29 \mathrm{~A}$ \\
& GII & 240 & $70 \pm 9,29 \mathrm{~A}$
\end{tabular}

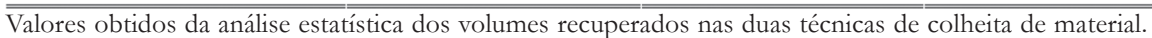

Letras maiúsculas iguais significam que não houve diferenças significativas entre os grupos $(\mathrm{P}<0,05)$ 
Tabela 3 - Valores médios e desvios-padrão dos constituintes dos hemogramas de eqüinos em ronda (GI) e afastados de atividades (GII) submetidos aos lavados broncoalveolares. Brasília, 2004

\begin{tabular}{|c|c|c|}
\hline Hemograma & Grupo I & Grupo II \\
\hline Hemácias x $10^{6} / \mu \mathrm{L}$ & $7,58 \pm 1,12 \mathrm{~A}$ & $7,77 \pm 1,03 \mathrm{~A}$ \\
\hline Volume globular (\%) & $35,8 \pm 5,30 \mathrm{~A}$ & $35,8 \pm 5,30 \mathrm{~A}$ \\
\hline Hemoglobina $(\mathrm{g} / \mathrm{dL})$ & $11,99 \pm 1,29 \mathrm{~A}$ & $12,18 \pm 1,25 \mathrm{~A}$ \\
\hline $\mathrm{VCM}(\mathrm{fl})$ & $47,32 \pm 6,64 \mathrm{~A}$ & $46,08 \pm 6,25 \mathrm{~A}$ \\
\hline $\mathrm{HCM}(\mathrm{pg})$ & $15,85 \pm 0,36 \mathrm{~A}$ & $15,63 \pm 0,61 \mathrm{~A}$ \\
\hline $\mathrm{CHCM}(\%)$ & $33,50 \pm 1,69 \mathrm{~A}$ & $33,92 \pm 1,56 \mathrm{~A}$ \\
\hline Leucócitos totais $\times 10^{3} / \mu \mathrm{L}$ & $8,5 \pm 2,01 \mathrm{~A}$ & $9,1 \pm 2,11 \mathrm{~A}$ \\
\hline Bastonetes $\mu \mathrm{L}$ & $170 \pm 55,21 \mathrm{~A}$ & $140 \pm 33,57 \mathrm{~A}$ \\
\hline Segmentados $\mu \mathrm{L}$ & $5600 \pm 1525,54 \mathrm{~A}$ & $6000 \pm 1496,66 \mathrm{~A}$ \\
\hline Neutrófilos totais $\mu \mathrm{L}$ & $5,71 \pm 1,35 \mathrm{~A}$ & $6,10 \pm 1,28 \mathrm{~A}$ \\
\hline Linfócitos $\mu \mathrm{L}$ & $2,46 \pm 1,16 \mathrm{~A}$ & $2,62 \pm 1,10 \mathrm{~A}$ \\
\hline Monócitos $\mu \mathrm{L}$ & $0,12 \pm 0,24 \mathrm{~A}$ & $0,12 \pm 0,22 \mathrm{~A}$ \\
\hline Eosinófilos $\mu \mathrm{L}$ & $0,28 \pm 0,34 \mathrm{~A}$ & $0,28 \pm 0,33 \mathrm{~A}$ \\
\hline Plaquetometria $\times 10^{3} / \mu \mathrm{L}$ & $233,7 \pm 23,65 \mathrm{~A}$ & $263,1 \pm 10,06 \mathrm{~A}$ \\
\hline
\end{tabular}

Valores oriundos da análise estatística do hemograma dos animais pertencentes a cada grupo.

Letras maiúsculas iguais significam que não houve diferenças significativas entre os grupos $(\mathrm{P}<0,05)$

Tabela 4 - Achados de artefatos, muco, leveduras e bactérias nos lavados broncoalveolares em eqüinos em ronda (GI) e afastados da escala (GII). Brasília, 2004

\begin{tabular}{cccccc}
\hline \hline & Grupo & Artefatos & Muco & Levedura & bactérias \\
\hline LBA & GI & ++ & ++ & +++ & ++ \\
GII & +++ & + & ++ & ++
\end{tabular}

Fonte: Material coletado de eqüinos do $1^{\circ}$ RPMon - DF.

$+=\operatorname{Raro}(1 /$ campo $)++=\operatorname{Pouco}(2$ e $3 /$ campo $)+++=$ Moderado $(4$ a $6 /$ campo $)$

Tabela 5 - Valores médios obtidos para as contagens celulares diferenciais ( $\% \pm$ DP) nos lavados broncoalveolares em eqüinos em atividade de ronda (GI) e afastados (GII). Brasília, 2004.

\begin{tabular}{ccccccc}
\hline \hline Grupo & Células escamosas & Células epiteliais & Macrófagos & Linfócitos & Eosinófilos & Eritrócitos \\
\hline GI & $25,25 \pm 7,3 \mathrm{~A}$ & $20,2 \pm 5,5 \mathrm{~A}$ & $22,2 \pm 6,23 \mathrm{~A}$ & - & $2,02 \pm 5,77 \mathrm{~A}$ & $-\mathrm{A}$ \\
GII & $31,0 \pm 9,47 \mathrm{~A}$ & $19,0 \pm 5,20 \mathrm{~A}$ & $43,0 \pm 13,88 \mathrm{~A}$ & - & $4,0 \pm 1,52 \mathrm{~A}$ & $3,0 \pm 1,0 \mathrm{~A}$
\end{tabular}

Fonte: Material coletado de eqüinos do $1^{\circ}$ RPMon - DF

Letras maiúsculas iguais significam que não houve diferenças significativas entre os grupos $(\mathrm{P}<0,05)$ 
avaliação laboratorial do material.

Os registros aqui exibidos conciliam com os de Pickles et al. ${ }^{7}$, em que todas as 24 alíquotas recuperadas foram consideradas adequadas para representação citológica baseando-se nos volumes recuperados, posto terem sido considerados satisfatórios para a representatividade celular.

A análise do material obtido confirmou os relatos de Halls e Gudmundsson ${ }^{9}$ visto terem sido identificados em animais de ambos os grupos, fungos, leveduras e componentes inorgânicos denominados artefatos.

Em acordo com a citação de Speirs ${ }^{8}$ de que as vias aéreas não são estéreis e existe a maior perspectiva de isolamento de bactérias e fungos em hospitais e estábulos, observou-se que a presença de bactérias, incluindo coccus e bastonetes, e de leveduras foi freqüente nos lavados dos dois grupos experimentais. Foi observado componente bacteriano evidente nos grupos experimentais, com, no entanto, magnitudes diferentes. Embora sem diferença estatística, houve distinção na aparição de leveduras quanto ao grupo experimentado, sendo este achado mais evidente nos eqüinos do grupo I.

No fluido do LBA de todos os animais confirmou-se o relato de uma camada de espuma sobre o líquido ${ }^{4}$, indicando a presença do surfactante, o que, por sua vez, reafirma o alcance do líquido lavado em nível alveolar.

A ocorrência de celularidade diversa, leveduras, artefatos, muco e bactérias em maior ou menor intensidade, mas presentes em todos os grupos trabalhados, concorda com McGorum ${ }^{10}$ de que fatores como a atmosfera das instalações, a apresentação do alimento e a utilidade do animal consistem em uma mescla variável de agentes que podem influenciar os resultados encontrados .

Os resultados encontrados nos LBAs não divergiram das descrições de Fogarty ${ }^{5}$, Fernandes, Mori e Sanches ${ }^{3}$, Viel ${ }^{11}$ e Viel ${ }^{12}$, mostrando-se seguro, executável sem dificuldades e nenhuma complicação neste estudo, o que viabiliza a sua inclusão nos procedimentos de rotina clínica.

\section{Conclusão}

Os exames clínicos, em consonância com a análise do hemograma e dos lavados broncoalveolares firmaram que todos os animais utilizados no experimento, apesar de constituírem grupos diferentes, apresentavam-se sem afecção do trato respiratório, confirmando a ausência de sintomas compatíveis com afecções respiratórias.

Frente à ampla variabilidade de elementos encontrados neste ensaio, a utilidade clínica do LBA pode mostrar-se limitada.

\section{Brochoalveolar wash citology from horses of the military police in the federal district}

\section{Summary}

The objective of this study was evaluate the airways' cells types from horses of the military police of Federal District. It was used 24 horses, divided into 2 groups of 12: group I - animals in policy activity and group II - animals out of policy activity. At the inspection, physical exam and blood exam, the results agreed with no present clinical pathologies. It was infused $240 \mathrm{~mL}$ of saline solution in the bronchoalveolar wash. In the bronchoalveolar wash, the group I registered $25.25 \pm 7.3$ squamous cells, $20.2 \pm 5.5$ epithelial cells, 22.2 \pm 6.23 macrophages and $2.02 \pm 5.77$ erythrocytes, and in the group II, it was observed $31.0 \pm 9.47$ squamous cells, $19.0 \pm 5.20$ epithelial cells, $43.0 \pm 13.88$ macrophages, $4.0 \pm 1.52$ eosinophile and $3.0 \pm 1.0$ erythrocytes. Verifying the occurrence of side effects after the experiment, there was no problem from the used technique.

Key words: Bronchoalveolar. Citology. Equine. Wash. 


\section{Referências}

1 GONÇALVES, R. C.; KUCHEMBUCK, M. R. G.; ALMEIDA, C. T. Lavagem traqueobrônquica por traqueocentese em bovinos. Veterinária e Zootecnia, v. 2, n. 2, p. 17-25, 1990.

2 GONÇALVES, R. C. Estudo clínico e citológico em bezerros clinicamente sadios e portadores de broncopneumonia moderada e grave - o lavado traqueobrônquico como complemento diagnóstico. 1997. 144 f. Tese (Doutorado em Patologia) - Faculdade de Medicina, Universidade Estadual Paulista, Botucatu, 1997.

3 FERNANDES, W. R.; MORI, E.; SANCHES, A. Avaliação citológica de lavados traqueobrônquico e broncoalveolar em cavalos clinicamente sadios pelo método de coloração de Rosenfeld. Arquivo Brasileiro de Medicina Veterinária e Zootecnia, v. 52, n. 6, p. 604-609, 2000

4 AMES, T. R. Infectious diseases of the respiratory system. In: KOBLUK, C. N.; AMES, T. R.; GEOR, R. J. The horse diseases \& clinical management. Philadelphia: W.B. Saunders, 1995. p. 207-210.

5 FOGARTY, U. Evaluation of bronchoalveolar lavage technique. Equine Veterinary Journal, v. 22, n. 3, p. 174-176, 1990

6 LAAN, T.T. et al. Bronchoaveolar lavage for the diagnosis of lower airway disorders in horses. Tijdschrift voor Diergeneeskunde, v. 126, n. 17, p. 554-559, 2001.

7 PICKLES, K. et al. Cytological analysis of equine bronchoalveolar lavage fluid. Part 2: Comparison of smear and cytocentrifuged preparations. Equine Veterinary Journal, v. 34, n. 3, p. 292-296, 2002.

8 SPEIRS, V. C. O sistema respiratório. In: SPEIRS, V.C. Exame clínico de eqüinos. Porto Alegre: Artmed, 1999. p. 37-81.

9 HALLS, T. E.; GUDMUNDSSON, B. Miles of stored hay in Iceland. Journal of Agricultural Research in Iceland, v. 17, n. 4, p. 31-37, 1985.

10 McGORUM, B. Environmental factors as aetiological agents. Equine Veterinary Journal, v. 33, n. 1, p. 5-19, 2001. International Workshop On Equine Chronic Airway Disease.

11 VIEL, L. Structural-functional correlations of the lung in the normal light horse. 1980. Dissertation (Magister Science) - University of Guelph, Guelph, 1980.

12 VIEL, L. Endoscopic scores, bronchoalveolar lavage and tracheobronquial cytology. Equine Veterinary Journal, v. 33, n. 1, p. 5-19, 2001. International Workshop On Equine Chronic Airway Disease. 